Loyalitas Kreativitas

Aldi Masyarakat Kreatif

\title{
OPTIMALISASI PERAN KELURAHAN DALAM RANGKA MENINGKATKAN FUNGSI KELURAHAN SEBAGAI FASILITATOR MASYARAKAT KELURAHAN PAMULANG BARAT KOTA TANGERANG SELATAN
}

\author{
Andri Priadi, Fauziah Septiani, Sairin, Supardi, Suharni Rahayu \\ Dosen Ekonomi Fakultas Ekonomi Universitas Pamulang
}

Email : dosen02160@unpam.ac.id, dosen01771@unpam.ac.id, dosen01517@unpam.ac.id, dosen00491@unpam.ac.id, dosen00964@unpam.ac.id

\begin{abstract}
ABSTRAK
Tujuan dari Kegiatan Pengabdian Kepada Masyarakat adalah untuk melaksanakan salah satu Tri Darma Perguruan Tinggi.Selain itu diharapkan dengan pengabdian kepada masyarakat tersebut keberadaan perguruan tinggi dapat memberikan kontribusi besar kepada pengembangan dan penerapan keilmuan kepada masyarakat.

Metode yang digunakan pada Pengabdian Kepada Masyarakat ini berupa penyampaian materi secara verbal dan pembelajaran yang menekankan pada proses berpikir kritis dan analitis terkait keilmuan manajemen sumber daya manusia dan pengembangan sumber daya manusia (pegawai kelurahan pamulang barat).

Dalam penyelenggaraan pelayanan kepada masyarakat, tentunya kelurahan sangat besar perannya sebagai fasilitator dalam berbagai aktivitas kependudukan, oleh karena itu dalam bidang pelayanan ini, SDM di Bidang pelayanan ditambahkan dengan menyelenggarakan perekrutan petugas administrasi bidang pelayanan dan IT untuk memperluas rentang kendali pelayanan Kelurahan Pamulang Barat. Lurah mempunyai tugas merencanakan, melaksanakan, mengarahkan, mengawasi, mengendalikan, menyelenggarakan pemerintahan Kelurahan sesuai dengan Tugas, Fungsi dan Tata Kerja Kelurahan .

Pengabdian kepada masyarakat di kelurahan Pamulang barat dilaksanakan selama tiga hari. Namun sebelum melaksanakannya, kami sudah melakukan beberapa kali kunjungan yang bertujuan agar kami bisa survey dan melaksanakan pengabdian kepada masyarakat dengan baik.

Tugas Pokok dan Fungsi secara umum merupakan hal-hal yang harus bahkan wajib dikerjakan oleh seorang anggota organisasi atau pegawai dalam suatu instansi secara rutin sesuai dengan kemampuan yang dimilikinya untuk menyelesaikan program kerja yang telah dibuat berdasarkan tujuan, visi dan misi suatu organisasi. Setiap pegawai seharusnya melaksanakan kegiatan yang lebih rinci yang dilaksanakan secara jelas dan dalam setiap bagian atau unit. Rincian tugas-tugas tersebut digolongkan kedalam satuan praktis dan konkrit sesuai dengan kemampuan dan tuntutan masyarakat. Tugas Pokok dan fungsi (TUPOKSI) merupakan suatu kesatuan yang saling terkait antara Tugas Pokok dan Fungsi. Dalam Peraturan Perundangundangan pun sering disebutkan bahwa suatu organisasi menyelenggarakan fungsi-fungsi dalam rangka melaksanakan sebuah tugas pokok. Melalui kegiatan pemberdayaan, individu dan masyarakat disadarkan akan potensi, kebutuhan dan masalah yang ada pada diri dan lingkungannya. Selanjutnya mereka didorong untuk mau melakukan perubahan yang dimulai dari dalam diri. Oleh sebab itu, kami mengambil judul Optimalisasi Peran Kelurahan Dalam Rangka Meningkatkan Fungsi Kelurahan Sebagai Fasilitator Masyarakat di kelurahan pamulang barat
\end{abstract}

\section{Kata Kunci: Optimalisasi, Peran dan Fasilitator}


Loyalitas Kreativitas Aldi Masyarakat Kreatil
P-ISSN 2722-2101, E-ISSN 2722-4201

Program Studi Ekonomi Manajemen Universitas Pamulang

Jurnal LOKABMAS Kreatif Vol.02,No.02.Juli 2021 Hal.58-61

Email:jurnalkreatif.manajemen@gmail.com

\begin{abstract}
ABSTRAC
The purpose of Community Service Activities is to carry out one of the Tri Dharma of Higher Education. In addition, it is hoped that with this community service the existence of universities can make a major contribution to the development and application of science to the community.

The method used in this Community Service is in the form of verbal delivery of material and learning that emphasizes critical and analytical thinking processes related to human resource management and human resource development (pamulang barat sub-district employees).

In providing services to the community, of course the sub-district plays a very large role as a facilitator in various population activities, therefore in this service sector, human resources in the service sector are added by recruiting administrative officers in the service sector and IT to expand the range of control of West Pamulang Kelurahan services. The Lurah has the task of planning, executing, directing, supervising, controlling, administering the Kelurahan administration in accordance with the duties, functions and work procedures of the Kelurahan.

Community service in the West Pamulang village is carried out for three days. However, before implementing it, we have made several visits with the aim of being able to survey and carry out community service properly.

Main Duties and Functions in general are things that must be done by a member of an organization or an employee in an agency on a regular basis according to their ability to complete work programs that have been made based on the objectives, vision and mission of an organization. Each employee should carry out more detailed activities that are carried out clearly and in each section or unit. The details of these tasks are classified into practical and concrete units according to the capacities and demands of the community. Main Duties and functions (TUPOKSI) are an interrelated unity between Main Duties and Functions. In the laws and regulations it is often stated that an organization carries out functions in order to carry out a main task. Through empowerment activities, individuals and communities are made aware of the potential, needs and problems that exist in themselves and their environment. Furthermore, they are encouraged to want to make changes that start from within. Therefore, we take the title Optimizing the Role of the Kelurahan in Order to Improve the Function of the Village as a Community Facilitator in the village of West Pamulang.
\end{abstract}

Keywords: Optimization, Role and Facilitator

\section{PENDAHULUAN}

Dalam penyelenggaraan pelayanan kepada masyarakat, tentunya kelurahan sangat besar perannya sebagai fasilitator dalam berbagai aktivitas kependudukan, oleh karena itu dalam bidang pelayanan ini, SDM di Bidang pelayanan ditambahkan dengan menyelenggarakan perekrutan petugas administrasi bidang pelayanan dan IT untuk memperluas rentang kendali pelayanan Kelurahan Pamulang Barat. Lurah mempunyai tugas merencanakan, melaksanakan, mengarahkan, mengawasi, mengendalikan, menyelenggarakan pemerintahan Kelurahan sesuai dengan Tugas, Fungsi dan Tata Kerja Kelurahan .

Untuk melaksanakan tugasnya Lurah mempunyai fungsi :

1. Menyusun Program Kerja dan kegiatan Kelurahan;

2. Mengatur kegiatan Kelurahan meliputi penyiapan perumusan kebijakan teknis dan operasional di Kelurahan;

3. Mengatur dan mendistribusikan tugas kepada bawahan sesuai tugasnya masingmasing;

4. Memberi petunjuk kepada bawahan dalam melaksanakan tugas sesuai ketentuan yang berlaku; 
5. Memeriksa hasil pelaksanaan tugas bawahan dan melakukan perbaikan apabila terdapat kesalahan-kesalahan;

6. Mengkoordinasikan penyelenggaraan pemerintahan diwilayah, dalam kegiatan pembangunan, sosial, ekonomi, pelayanan masyarakat, serta pemberdayaan masyarakat agar terpadu dan terarah;

7. Memfasilitasi penyelenggaraan urusan pemeritahan umum dan agrarian, pembinaan lembaga kemasyarakatan serta pembinaan ketentraman dan ketertiban umum di wilayah;

8. Menyusun program/kegiatan administrasi ketatausahaan dan rumah tangga Kelurahan; Memfasilitasi pembentukan, penggabungan wilayah Rukun Warga/Rukun Tatangga dilingkungan Kelurahan;

9. Mengkoordinasikan pelaksanaan pemeliharaan prasarana dan fasilitas umum dengan Satuan Kerja Prangkat Daerah atau instansi terkait

10. Mengevaluasi kegiatan sesuai hasil yang telah dicapai;

11. Melaksankan tugas-tugas kedinasan lain yang diberikan oleh Camat baik lisan maupun tertulis dalam rangka pelaksanaan tugas. Lurah dalam menjalankan tugasnya dan bertanggungjawab kepada camat.

Tugas Pokok dan Fungsi secara umum merupakan hal-hal yang harus bahkan wajib dikerjakan oleh seorang anggota organisasi atau pegawai dalam suatu instansi secara rutin sesuai dengan kemampuan yang dimilikinya untuk menyelesaikan program kerja yang telah dibuat berdasarkan tujuan, visi dan misi suatu organisasi. Setiap pegawai seharusnya melaksanakan kegiatan yang lebih rinci yang dilaksanakan secara jelas dan dalam setiap bagian atau unit. Rincian tugastugas tersebut digolongkan kedalam satuan praktis dan konkrit sesuai dengan kemampuan dan tuntutan masyarakat. Tugas Pokok dan fungsi (TUPOKSI) merupakan suatu kesatuan yang saling terkait antara Tugas Pokok dan Fungsi. Dalam Peraturan Perundang-undangan pun sering disebutkan bahwa suatu organisasi menyelenggarakan fungsi-fungsi dalam rangka melaksanakan sebuah tugas pokok. Melalui kegiatan pemberdayaan, individu dan masyarakat disadarkan akan potensi, kebutuhan dan masalah yang ada pada diri dan lingkungannya. Selanjutnya mereka didorong untuk mau melakukan perubahan yang dimulai dari dalam diri.

\section{RUMUSAN MASALAH}

Adapun perumusan masalah adalah pada PKM ini adalah:

1. Bagaimana Program Peningkatan Peran Kelurahan untuk tujuan peningkatan kesejahteraan masyarakat di sekitaran kelurahan pamulang barat kecamatan pamulang kota tangerang selatan?

2. Sejauh mana kelurahan memfasilitasi Peningkatan Perekonomian Masyarakat yang berperan sebagai fasilitator bagi pengembangan perekonomian masyarakat, melalui kegiatan kelurahan pamulang barat kecamatan pamulang kota tangerang selatan?

\section{TUJUAN PELAKSANAAN}

Tujuan dari PKM ini adalah:

1. Untuk memberikan penyuluhan Bagaimana Program Peningkatan Peran Kelurahan untuk tujuan peningkatan kesejahteraan masyarakat di sekitaran kelurahan pamulang barat kecamatan pamulang kota tangerang selatan.

2. Untuk meningkatkan pengetahuan dan pemahaman Peningkatan Perekonomian Masyarakat yang berperan sebagai fasilitator bagi pengembangan perekonomian masyarakat, melalui kegiatan kelurahan pamulang barat kecamatan pamulang kota tangerang selatan

\section{TINJAUAN PUSTAKA}

Peran di definisikan sebagai corak perilaku yang diharapkan, yang seharusnya dimiliki seorang yang menduduki salah satu posisi dalam sebuah unit sosial. Pengertian tentang prilaku yang di perankan akan menjadi sangat sederhana andaikan setia individu diantara kita memilih satu peran dan memainkannya secara regular dan konsisten. Salah satu cara mempelajari priaku seseorang adalah dengan mempelajari peran yang sedang dimainkannya ini. Menurut Sumadiningrat 
Loyalitas Kreativitas Aldi Masyarakat Kreatif mengemukakan pendapat dalam Dahuri dan Nugroho (2004:26) bahwa peranan pemerintah saat ini sebagai fasilitator, regulator dan motivator dalam penyediaan prasarana public.

Riyadi (2004:26) mengatakan bahwa perencanaan pembangunan daerah berperan sebagai negosiator, moderator dan evaluator. Masyarakatlah sebagai perilaku utama pembangunan dan peran aktif masyarakat dapat berarti berperan langsung dalam berbagai proses politik dan perwakilan dalam proses perumusan program, dalam pelaksanaan dan pengawasan. Maka untuk kegiatan perencanaan masyarakat sendiri (yang terhimpun dalam lembaga forum lintas pelaku setempat). Yang selayaknya mampu untuk merumuskan kegiatan pembangunan apa yang cocok di wilayahnya.

Thoha (2005:263) mengatakan bahwa suatu peranan di rumuskan sebagai suatu rangkaian perilaku yang teratur, yang ditimbulkan karena suatu jabatan tertentu, atau karena adanya suatu kantor yang mudah dikenal.

Berdasarkan beberapa konsep diatas dapat disimpulkan bahwa peran merupakan hak dan kewajiban yang harus dilakukan seseorang/instansi berkaitan dengan kedudukan, tugas dan fungsinya dalam fasilitas yang diberikan oleh masyarakat. Peran didefinisikan secara istilah merujuk pada perilaku yang diharapkan dan seseorang yang menduduki suatu status tertentu, sehingga secara anologi

Peran Lurah adalah perilaku yang di harapkan dilakukan oleh Lurah berserta perangkatnya dalam menjalani pemerintahan.

\section{KESIMPULAN DAN SARAN Kesimpulan}

Kesimpulan dari pengabdian ini adalah sebelumnya para pegawai kelurahan merasa penting terkait peranya tentang bagaimana cara mengoptimalkan sumber daya yang dimiliki denganmengoptimalkan kinerjanya dalam rangka memberikan pelayanan terbaik kepada masyarakat kuhusunya di daerah kelurahan pamulang barat.

Oleh karena situasi sekarang, para pegawai kelurahan Pamulang barat tetap harus maksimal dalam memberikan pelayanannya kepada masyarakat. Maka setelah kegiatan PKM selesai dilakukan, para peserta mendapatkan banyak manfaat secara langsung baik berupa moril dan materil sebagai bekal ilmu untuk menghadapi tantangan yang ada khususnya masa pandemi covid-19.

\section{Saran}

Dengan pengabdian ini, kami selaku pengabdi dapat memberikan ilmu pengetahuan dan memotivasi agar para peserta tetap semangat bekerja dan melayani masyarakat khususnya masyarakat yang terdampak pandemi Covid-19. Pada kegiatan ini diharapkan juga mampu memberikan semangat baru bagi para dosen sebagai kontributor yang memotivasi khususnya bagi masyarakat sekitar yang membutuhkan bantuan, terlebih disaat pandemi covid-19 yang masih ada.

\section{DAFTAR PUSTAKA}

Gary Dessler. Human Personalia

Management Ninth Edition. Prentice Hall, New Jersey.

Gary Yukl. Leadership In Organization Seventh Edition. 2010. Pearson, Newyork.

Krisnaldy, K., Pasaribu, V. L. D., \& Senen, S. (2019). Pengaruh Budaya Organisasi, Lingkungan Kerja Dan Iklim Organisasi Terhadap Motivasi Pegawai Serta Dampaknya Terhadap Kepuasan Kerja. Jurnal Semarak, 2(2), 164-183.

Krisnaldy, K., Pasaribu, V. L. D., \& Batubara, A. S. (2020). Analisis Pengaruh Kedisiplinan Terhadap Performa Pegawai Kelurahan Rempoa, Kota Tangerang Selatan. Jurnal Mandiri: Ilmu Pengetahuan, Seni, Dan Teknologi, 4(2), 131-138.

Malayu S. P. Hasibuan. Manajemen Sumber Daya Manusia. 2007. Bumi Aksara, Jakarta.

Marihot T. E. Hariandja. Manajemen Sumber Daya Manusia. 2007. Grasindo, Jakarta.

Pasaribu, V. L. D., Krisnaldy, K., \& Warasto, H. N. (2020). Pengaruh Gaya 
Loyalitas Kreativitas Aldi Masyarakat Kreatif
Program Studi Ekonomi Manajemen Universitas Pamulang Jurnal LOKABMAS Kreatif Vol.02,No.02.Juli 2021 Hal.58-61

Email:jurnalkreatif.manajemen@gmail.com

Kepemimpinan, Disiplin Kerja Dan Kompensasi Terhadap Kinerja Pegawai (Studi kasus kelurahan Pisangan Ciputat). Jurnal Disrupsi Bisnis: Jurnal Ilmiah Prodi Manajemen, Fakultas Ekonomi, Universitas Pamulang, 3(1).

Pasaribu, V. L. D., \& Krisnaldy, K. (2020). PENGARUH GAYA KEPEMIMPINAN, DISIPLIN KERJA DAN KOMPENSASI TERHADAP HASIL KINERJA KARYAWAN KELURAHAN PISANGAN CIPUTAT. PROCEEDINGS UNIVERSITAS PAMULANG, 1(1).

Stephen Robbins. P dan Timothy Judge A. Organizational Behavior. 2009. PrenticeHall, New Jersey.

Sedarmayanti. Tata Kerja Dan Produktivitas

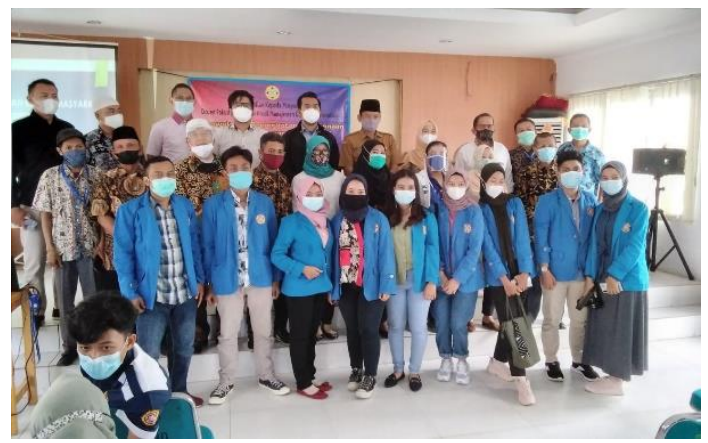
Kerja. 2007. CV Mandar Maju, Bandung.

T. Hani Handoko. Manajemen Personalia Dan Sumber Daya Manusia UGM. 2005. BPFE, Yogyakarta.

Veithzal Rivai dan Sylviana Murni. Education Management, Analisis Teori dan Praktek. 2009. Rajawali Pers, Jakarta.

\section{FOTO DOKUMENTASI}
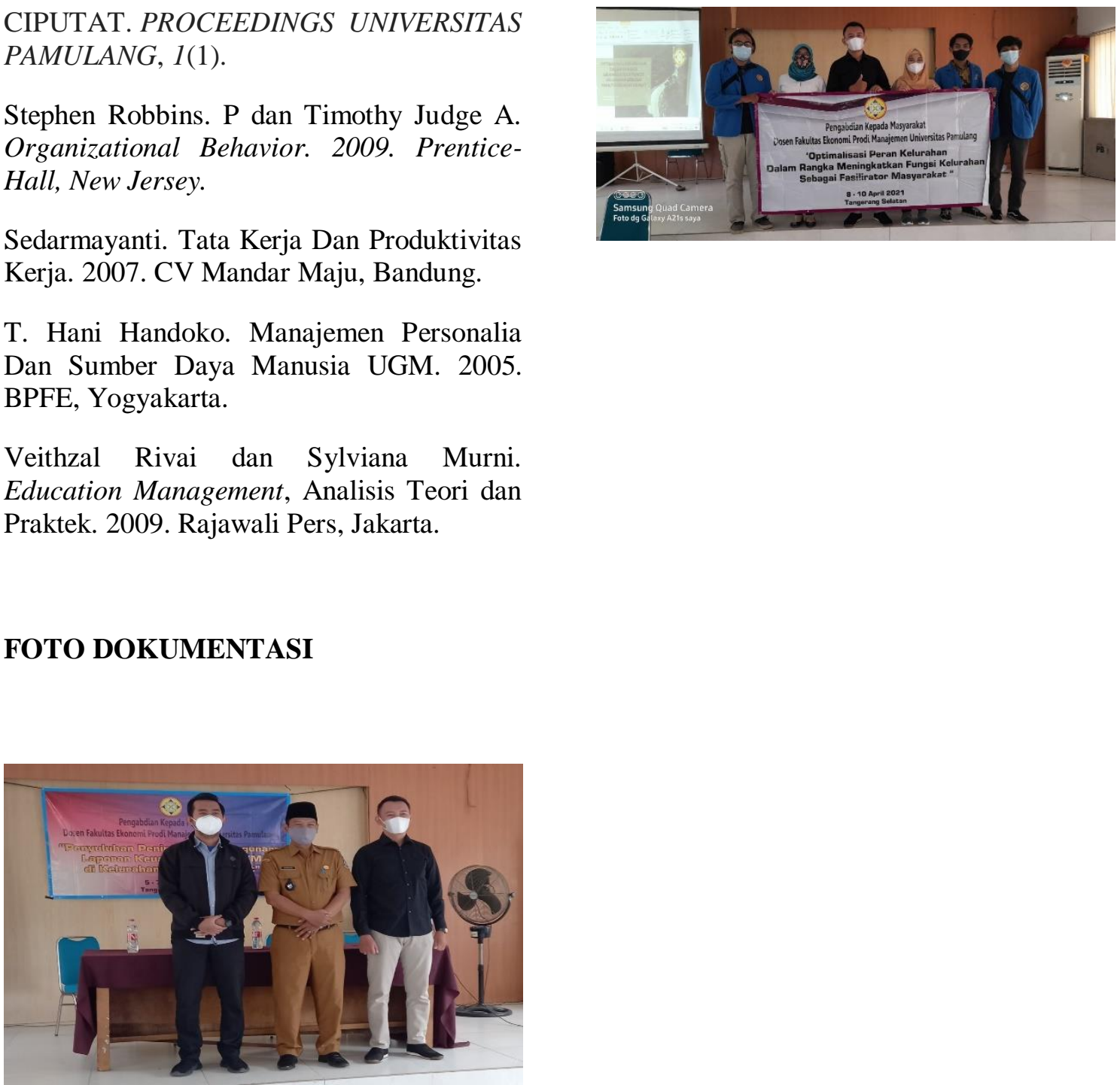